\title{
Health care providers' and mothers' perceptions about the medicalization of female genital mutilation or cutting in Egypt: A cross-sectional qualitative study [Arabic]
}

Omaima El-Gibaly

Mirette Aziz

Follow this and additional works at: https://knowledgecommons.popcouncil.org/departments_sbsr-rh

Part of the Demography, Population, and Ecology Commons, Family, Life Course, and Society Commons, Gender and Sexuality Commons, International Public Health Commons, and the Medicine and Health Commons How does access to this work benefit you? Let us know!

\section{Recommended Citation}

El-Gibaly, Omaima and Mirette Aziz. 2020. "Health care providers' and mothers' perceptions about the medicalization of female genital mutilation or cutting in Egypt: A cross-sectional qualitative study [Arabic]," Evidence to End FGM/C: Research to Help Girls and Women Thrive. Cairo: Population Council. 


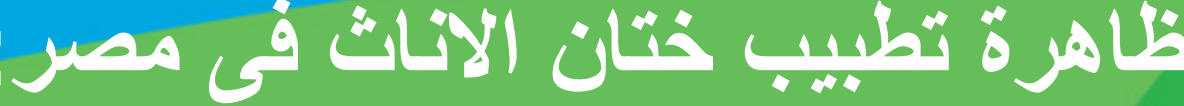 وجهات نظل مقاهى الخدمة الصحية

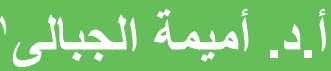

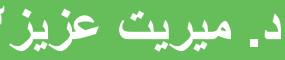

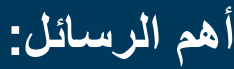

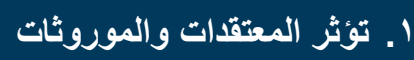
الثقافية بشكل قوى في استمرار ممارسة الختان سواء من جاتب فئب التبات

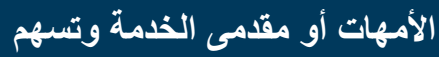
بثكل رئيسى في تطبيب الغتان.

r. الإعتقاد السائد لدى معظم الأمهات

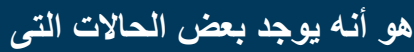

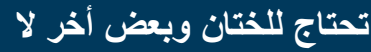
يحتاج، لألك فهم يالجأن للأطباء كمصدر موثوق به لتحديد ذلك.

r. معلومات الاطباء والممرضات حول الصحه الجنسيه محدوده

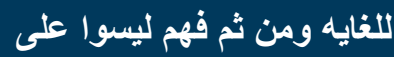
درايه كافيه باضرار الثتان.

ع. بالرغم من أن معظم الاطباء علي دراية بعدم قانونية الختّان

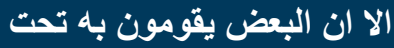

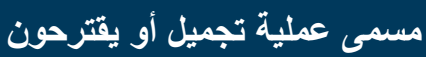
للأمهات أطباء اخرين يقومون بالممارسة. هـ ان القضاء على ظاهرة ختان

الاناث يتطلب العمل بالتوازى على التى خذض جاتبى العرض والطلب من خلال رفع وعى الاطباء والممرضات واتخاذ اجراءعات الاعباء رادعه مع الاطباء والممرضات واتهات

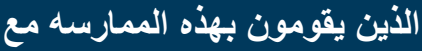
رفع الوعى لدى الاسر بالجواتب الصحيه والدينيه والقانونيه الإنتان.

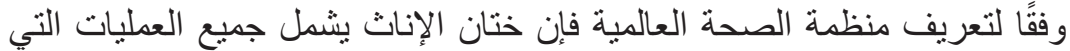

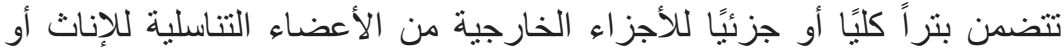

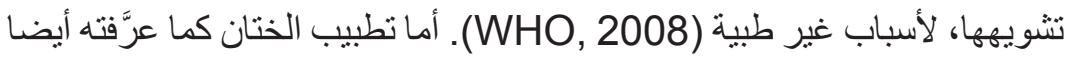

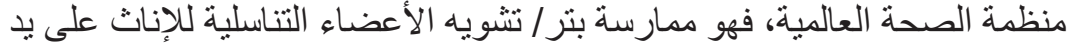

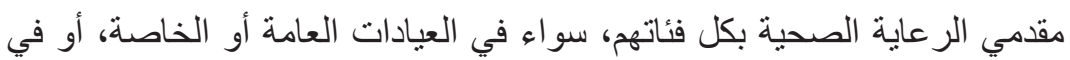

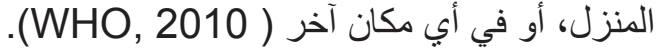

تشير نتائج المسوح و الدراسات إلي انخفاض في معدلات ختان الإناث في مصر، إنات

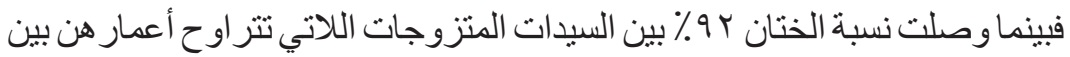

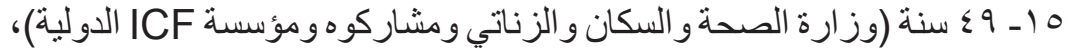

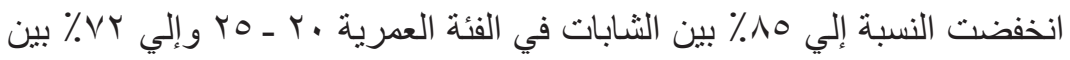

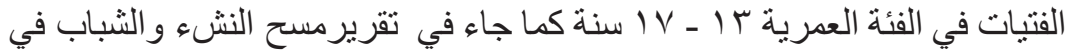

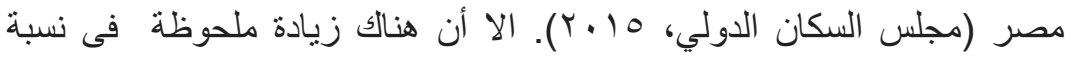

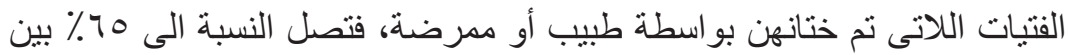

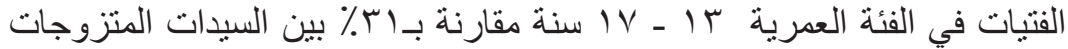
و اللاتي تتر اوح أعمار هن بين 10 ـ 9 ـ سنة.

و هنالك العديد من العو امل التى يمكن ان تكون قد اسهمت فى تطبيب ختان الاناث

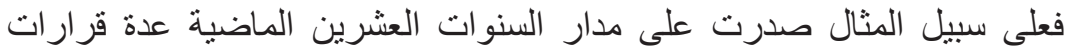

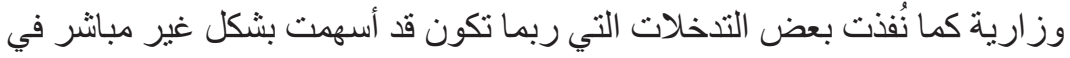

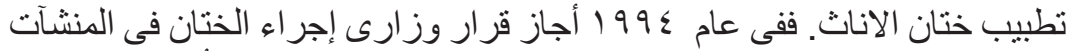

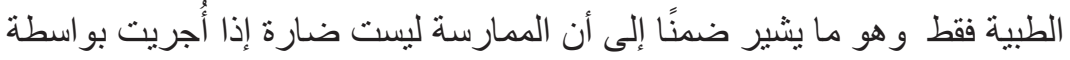

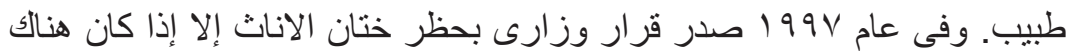

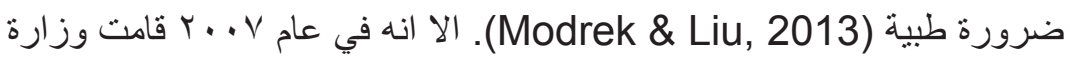

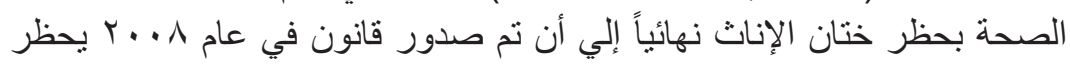
ختان الإناث ويجعله جريمة يُعاقب عليها القانون.

علاوة على ذلك، ربما تكون الحملات الإعلاميه السابقه قد اسهمت فى تطبيب ختان الإناث حيث انها ركزت على المضاعفات قصيرة المدى لختان الإناث وتحديدًا النزيف و الوفاة ومن ثم فإن العديد من الأسر بدأت تلجأ إلى الفريق الطبى تجنباً لحدوث تلك المضاعفات (Modrek \& Sieverding, 2016). 
نتيجة أخطاء الداية في اجر اء الختان، وأن الأطباء و الممرضات اكثر دراية بكيفية اجر اء العمليه.

وقد ذكرت المشاركات أن الأطباء و الممرضات مصدر موثوق

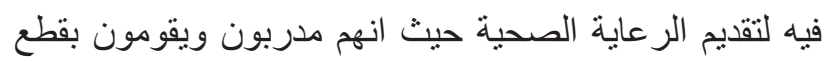

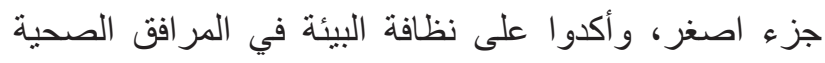

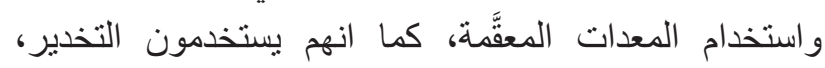
ويتابعون الحالة الصحية للفتيات بعد الختان.

\section{الطهارة الدابية غبر الدكتور، الدابية طهارتها}

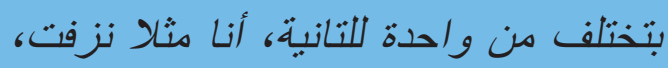

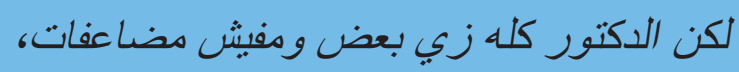

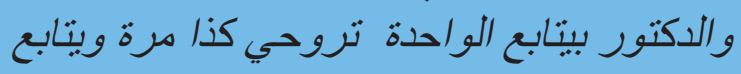

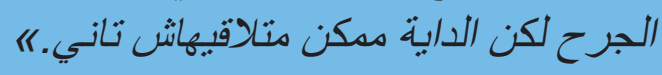
أم من محافظة أسبوط

\section{تحديل ما اذا كانت الحاله تحتاج للختان ام لا}

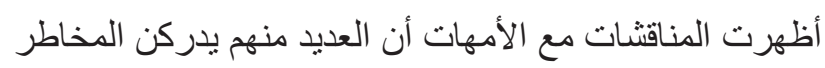

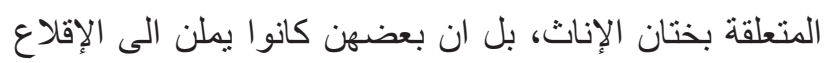

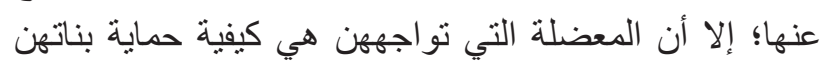

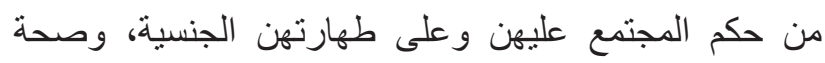
أعضائهن الجنسية فى حالة عدم الختان.

كما تبين من المجموعات البؤرية مع الأمهات أن الكثير منهم

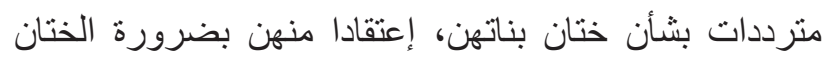

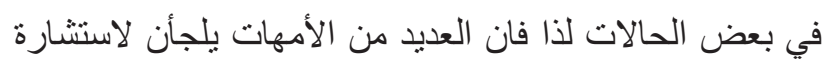

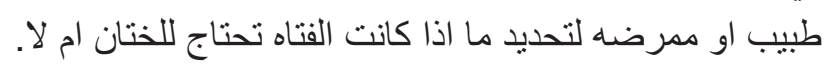

الهي بنت تبقي مش عاوزة طهارة مطهر اها

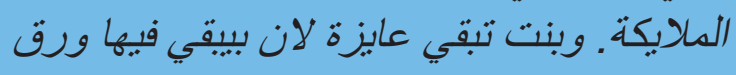
لازم تتطاهر ولند

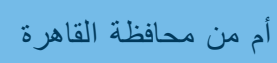

الالدكتور هو لبه الرأى الاول والاخبر برضه

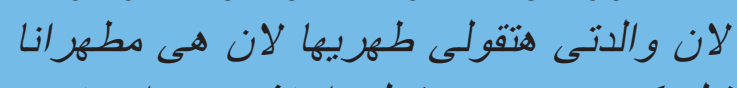

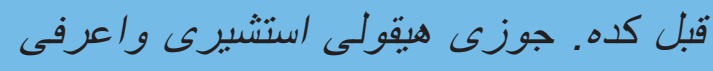

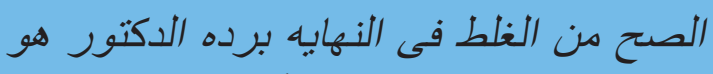

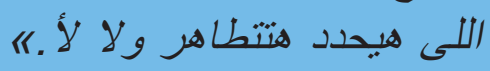

أم من محافظة الغربية

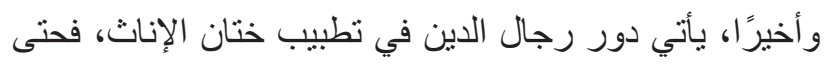

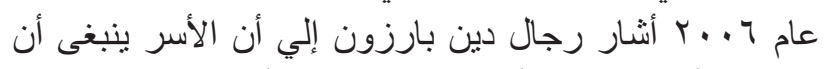

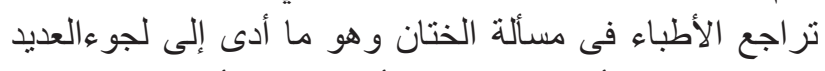

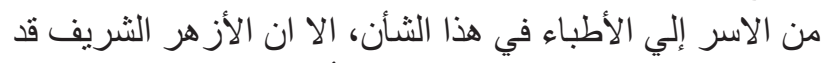

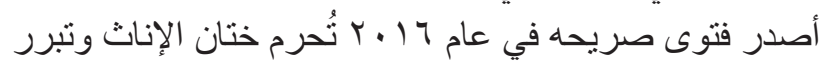

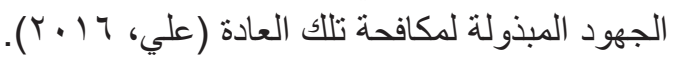

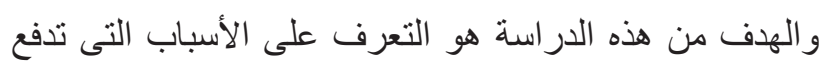

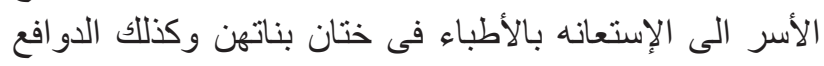

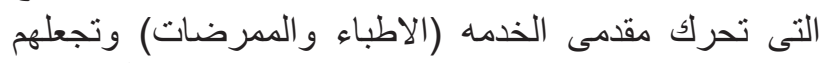

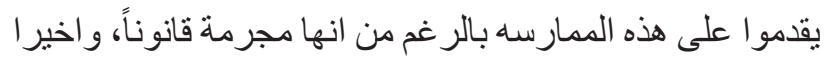

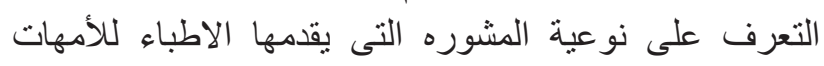
اللاتى ير غبن فى ختى نوعن بناتهن.

\section{منهجية الدراسة}

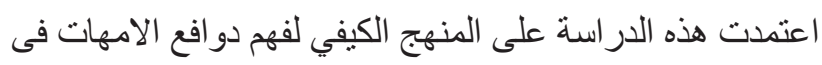

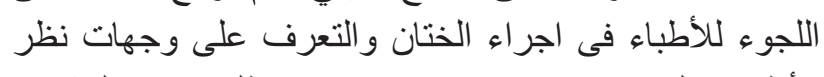

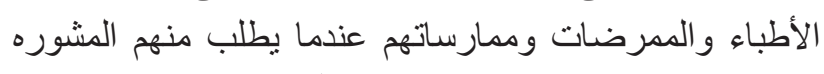
بخصوص ختان الاناث. وقات جمعت الدراسة بيانات من ثنات

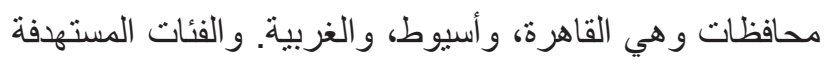

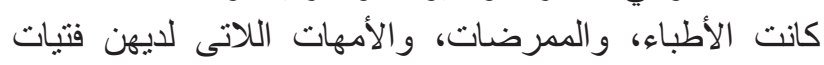

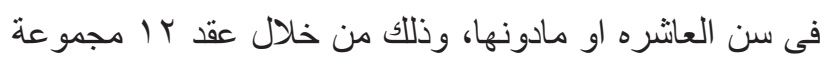

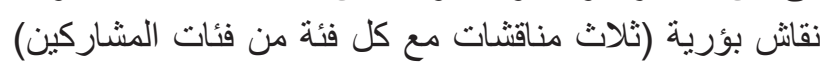

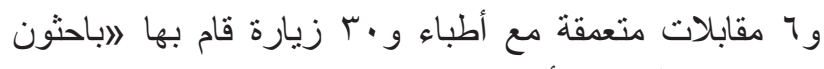

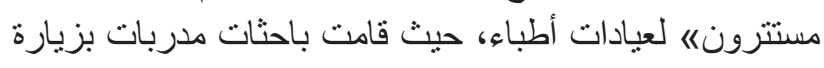

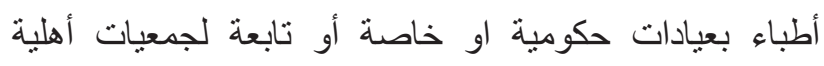

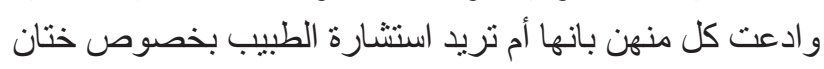

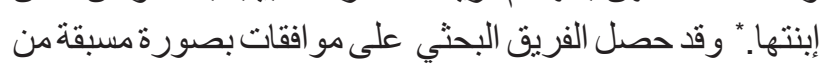

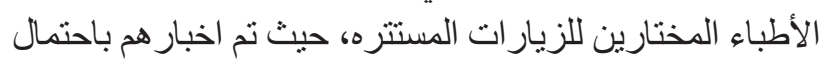

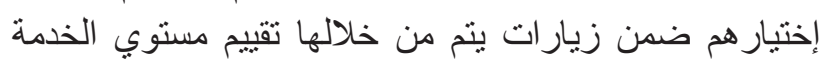

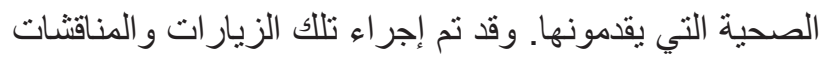

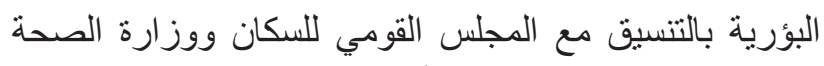

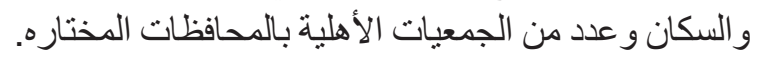

\section{اهم التتائج}

\section{لماذأ تُّأ بعض الأسر إلى الأطباء

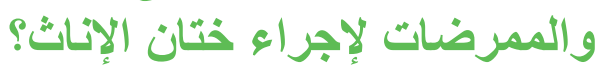

\section{تقليل احتمالات المضاعفات والاعراض الجانبيه}

يوجد تصور لدي بعض الأمهات أن المشكلات المرتبطة بختان

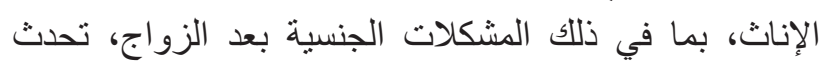


الالمشوره الجنسبه دي اجتهاد شخصي

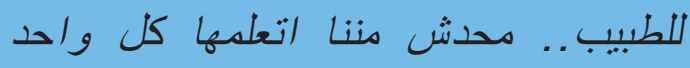

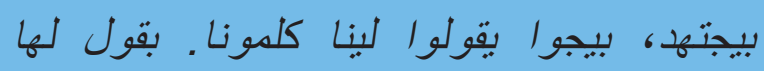

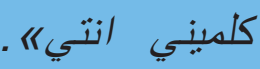

طبيبة من محافظة الغربية

وقد ساهم غياب الوعي لدي الأطباء والممرضنات فى إنتشار معتقدات غير صحيحة عن الفوائد الصحية والتجميليه لختان الإناث، إذ تبيِّن أن بعض الأطباء و الممرضات يرون ختان

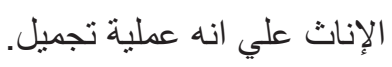

رام بسمبه ختان بسمبه تهذيب، بالنسبة لى

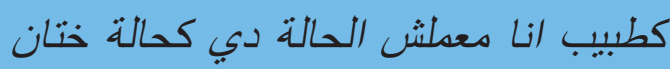

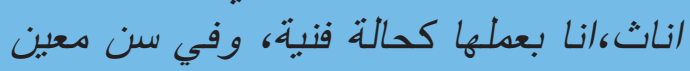

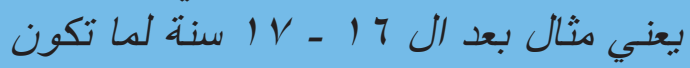

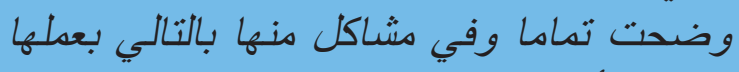
كتهذيب أو عملية تجمبيل بعني." طبيب من محافظة الغربية

الما الزوائد الجلدية بتبقي اعلي من ان

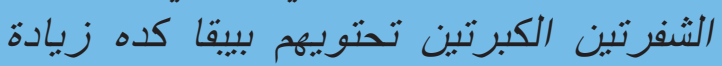

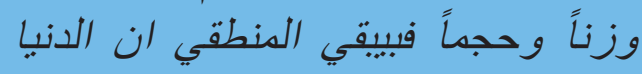

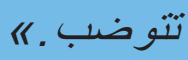

ممرضة من محافظة القاهرة

\section{الاقتناع بأهمية ختان الإناث}

لا ز الت هناك قناعات شخصية لدى بعض الأطباء و الممرضات

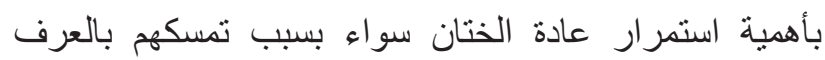

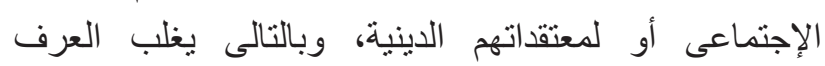
الإجتماعى أو المعتقد الدينى على الخوف من القانون او الالكنزام

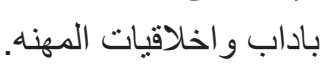

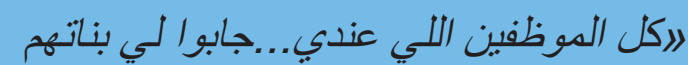

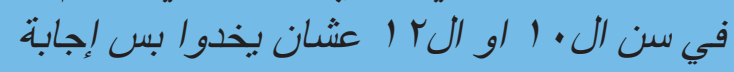

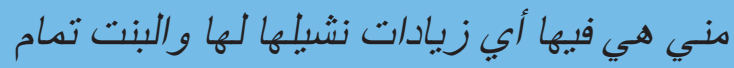

«.

ممرضة من محافظة القاهرة

$$
\text { الخوف من البرود الجنسي بعد الزواج }
$$

بالر غم من انه ماز ال الربط ما بين عفة وطهارة الفتاه و الختان

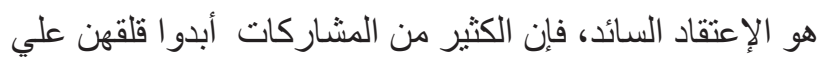

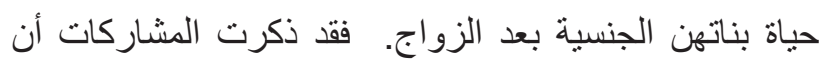
إستئصال جزء كبير من العضو التناسلي قد بيؤثر علي أنوثنة

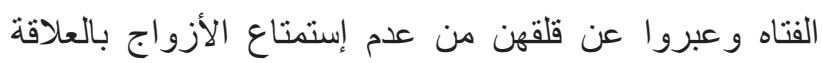
الجنسية معهن في هذه الحالة.

ومن ثم فهم يلجأن للأطباء لختان بناتهن على اعتبار انهم

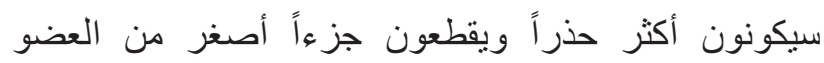

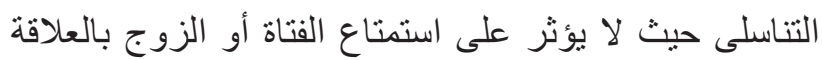

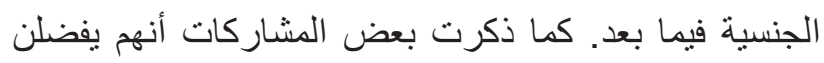

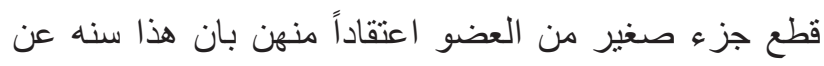
النبى (صلى الله عليه وسلم).

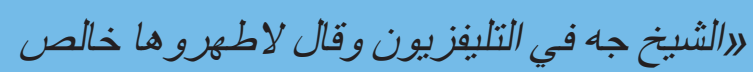

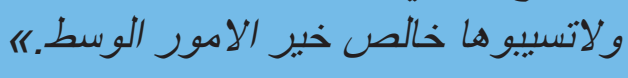

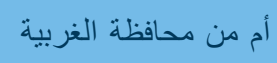

لماذا يقبل الأطباء والممرضات على اجراء ختان الاناث؟

\section{عدم الوعي بمفهوم الصحة الجنسية}

اتضح من خلال مجموعات النقاش البؤرية أن عدد قليل من

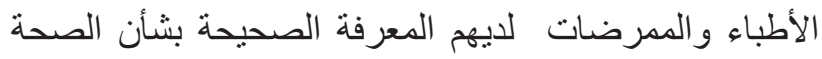

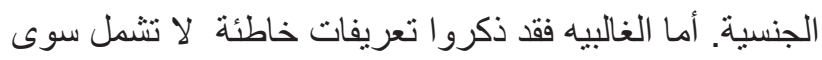

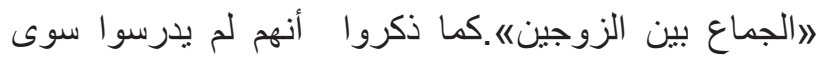

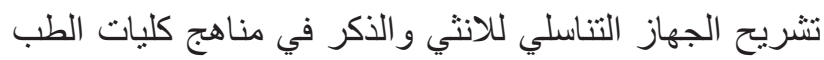
او التمريض، ولم يتلقوا أي معلومات بشأن الصحة الجنسية. 
ماهى ردود افعال الاطباء تجاه اسئلة الامههات

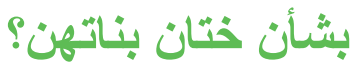

طلب الكثف على القتاه لتحديا درجة احتياجها للختان الغالبية العظمي من الأطباء الذين نم مقابلتهم في الزيارات

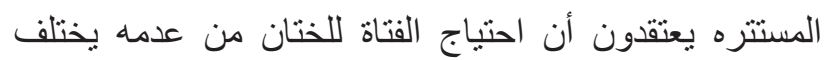
من حالة لأخرى حسب حجم العضو التناسلي. وقد اتفق هؤلاء الاطباء على أن ضرورة الختان متعلقة بحجم الثفرين و إز التهم الته لاء تكون لأسباب تجميليه فقط.

الا ان هناك طبيبان طلبا الكثف علي حجم بظر الفتاه لتحديد

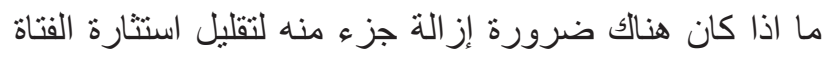

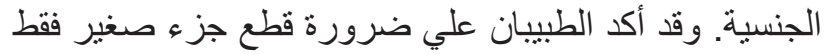
من البظر كي لا يؤثر علي الإستمتاع بالعلاقة الجنسية بعد فئرة

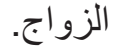

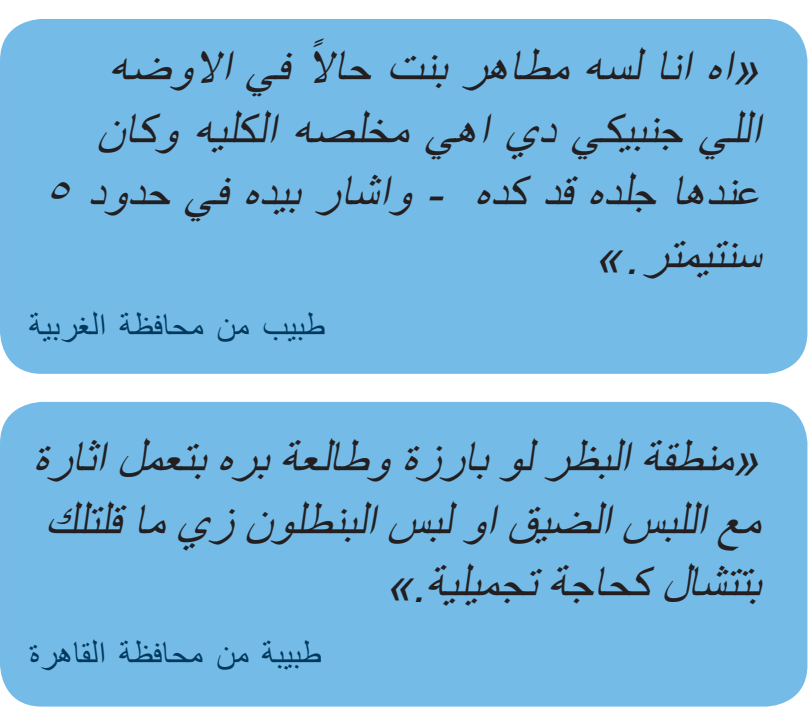

وقد تبين من الزيارات المستتره أن أغلبية الأطباء نصحوا

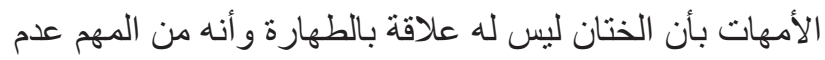

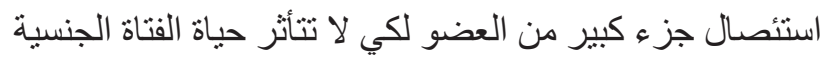

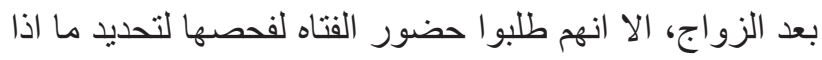

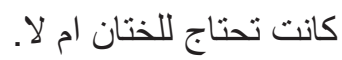

رفض فكرة الختان

مما يذكر ان اثثين فقط من الاطباء الذين شاركا فى الزيارات

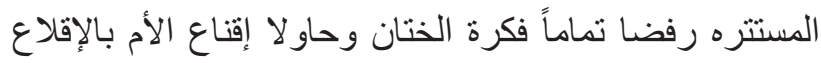

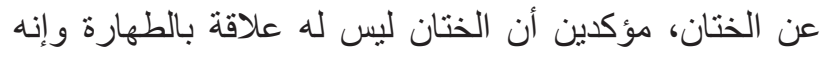

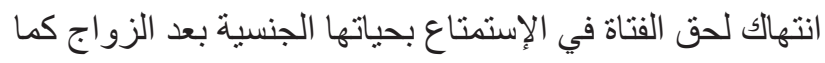
أصر ا على انه ليس له علاقة بالدين و انه غبر قانوني.

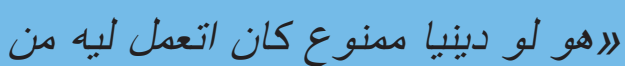

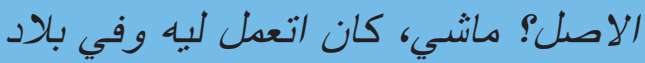

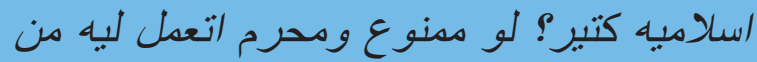

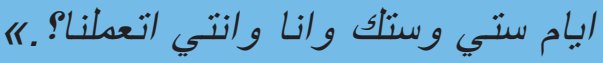
طبيبة من محافظة الغربية

لابصي هقول للك على حاجة. ساعات انتي

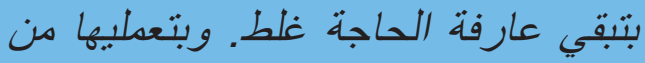

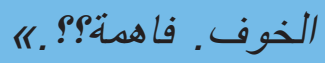

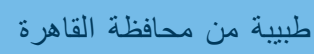

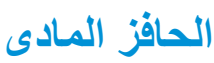

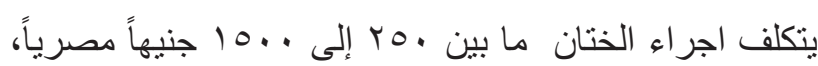

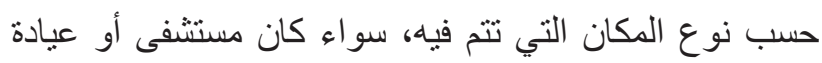
و هو ما يمثل حافزاً مادياً لبعض الأطباء.

اليا جماعه الطهارة في مصر ملهاش دعوه

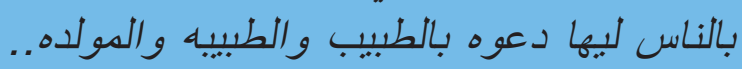

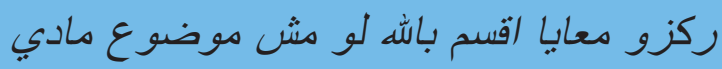

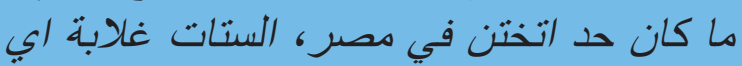

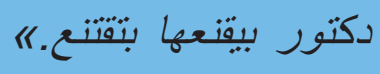

طبيبة من محافظة الغربية

علاوة على ذللك، فإن الأطباء الذين لا يقومون بإجراء عمليات

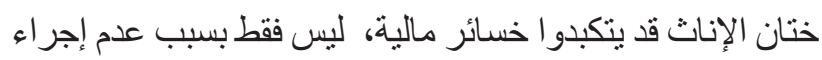
تلك العمليات، بل لأنه يتم وصمهم بعدم اتباع لعادات وتقاليد الئل مجتمعهم مما يتسبب في فقدان سمعتهم في المجتمع وثقة أفر اده.

راكتر من • ه ٪ من الدكاترة اللي في القري

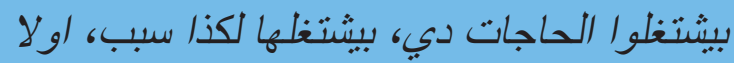

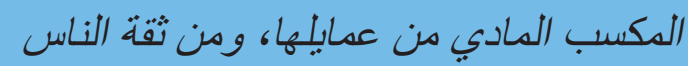

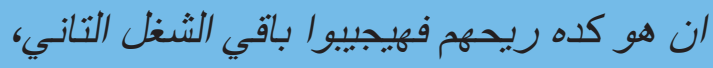
الحاجة التانبة ان هو لو مان ما عملهاش هيبقي

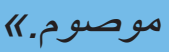

طبيب من محافظة القاهرة 
مزاولة الختان تحت مسمي آخر

رغم ان غالبية الأطباء الذين شاركوا في المقابلات المستتره

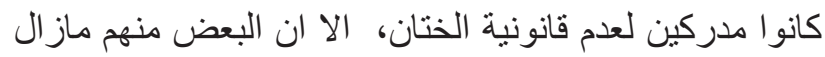

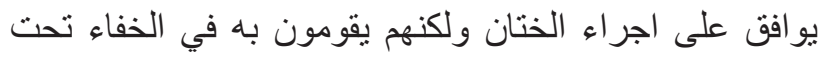
مسمي اخر مثل لاستتئصال كيس دهني" ولغئ.

الالمستشفي مالها انا بكتب تقربري هو لبه الحاله

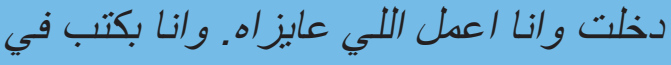
تقريزي كبس دهني في المهبل. طبيبة من محافظة القاهرة أثثاء المقابلة مع الباحثة المستتره

النصيحه بالتأجيل لحين بلوغ القتاه سن اكبر لقد تبين من خلال المقابلات المستتره مع الأطباء أن بعضهم الأنجا

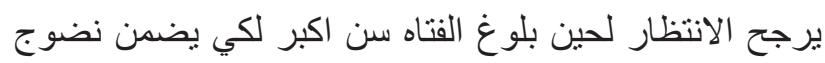

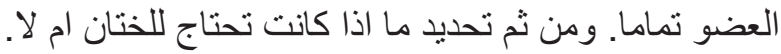

الأ بالعكس. و هي صغبرة هنكبر تاني وتقول للك

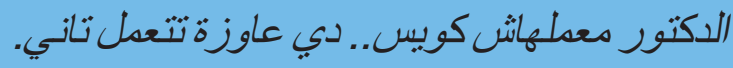

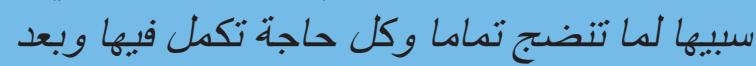

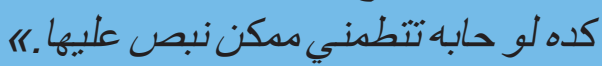
طبيب من محافظة القاهرة أثناء المقابلة مع الباحثة المستتره

و افاد بعض الأطباء انهم يفضلون الحصول على موافقة الفتاة

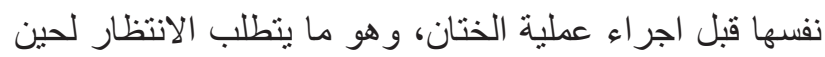
بلوغ الفتاه سن اكبر حتى تسنطيع اتخاذ القرار بنفسها.

لالا صغبره.. دي لازم البنت تكون عدت 17

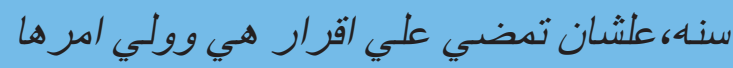

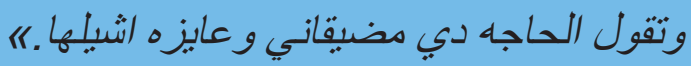
طبيبة من محافظة القاهرة أثناء المقابلة مع الباحثة المنتتره

\section{الخلاصه}

تشير نتائج الدراسه الى ان مقدمى الخدمه الصحيه (خاصة

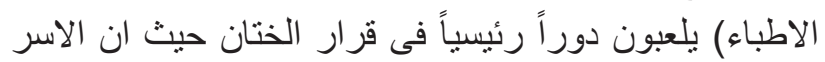

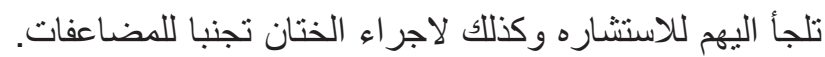

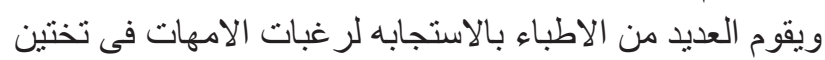

ارتطمريها لبه؟ الطهارة مهنوعة انتي ناسية

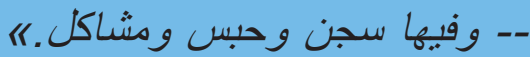

طبيب من محافظة القاهرة أثناء المقابلة مع الباحثة المستتره

وفي احدى الزيار ات طلبت الباحثة المستتره مشورة الطبيب

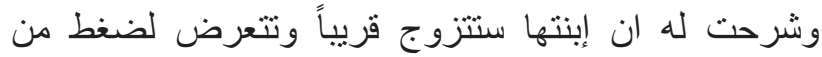

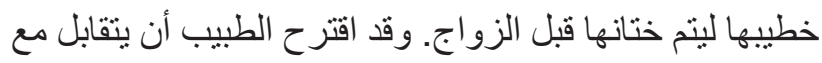
خطيب الفتاة لكي يقنعه بعدم الإصرار علي ختانها.

راقوليلهم ان ده خطر علي حباتها و الدكتور

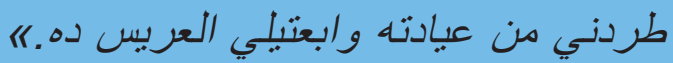
طبيب من محافظة الغربية أثناء المقابلة مع الباحثة المستتره

تحويل الحالة لطبيب اخر

لقد تبين من خلال المقابلات المستتره مع الأطباء أن بعضهم

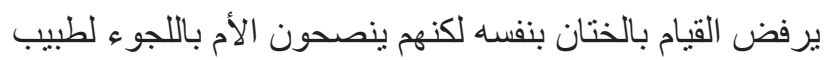
اخر كي يقوم بالختان.

في بعض الأحيان كان الأطباء يلجأون لذلك لعدم إقتناعم بالختان

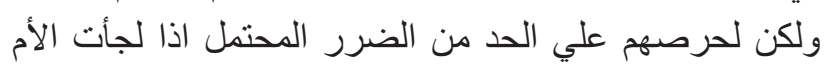

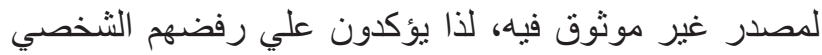
للختنان ولكن يقترحون علي الأم طبيباً اخر.

الو مصدمة اعرضيها علي دكتور نسا بس فيس

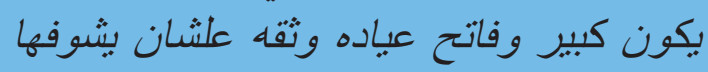

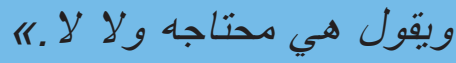

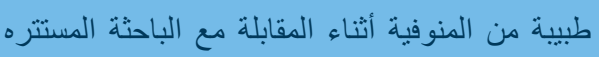

وفي أحيان أخري يكون الدافع للتحويل نابعاً من إقتناع الطبيب

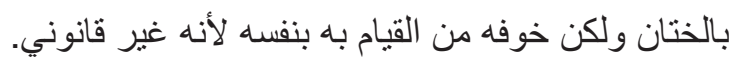

الانا كنت بعمل (ختان) بس بعد القانون اللي عمله

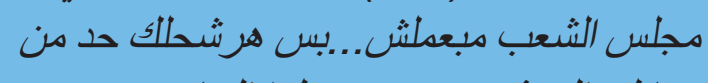

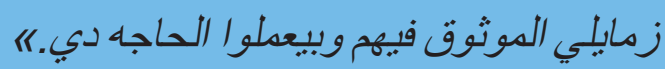
طبيبة من محافظة الغربية أثناء المقابلة مع الباحثة المستتره 
يتناول التدريب الجوانب الدينية و الأخلاقية و القانونية لممارسة ختان الإناث كما يجب أن يكتسب فريق التمريض فهرًا ولتا واضحًا

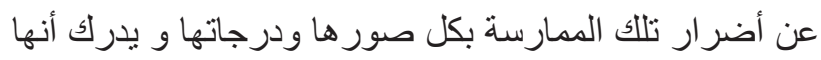

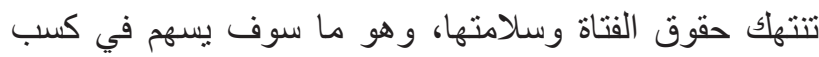
تأييدهم في القيام بالدعوة للإقلاع عن هذه وناء الممارسة.

\section{توصية ع : المر اقبة علي المستشثفيات الخاصة

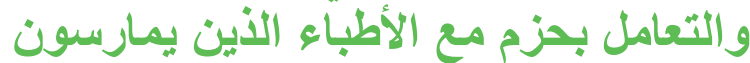

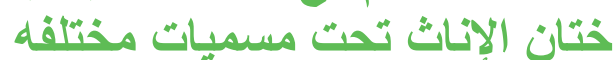

ينبغى اجر اء دور ات تفتيشيه على المستشفيات الخاصة لاكتشاف الحالات التى تسجل على انها از الة كيس دهنى وخاصة للفتيات

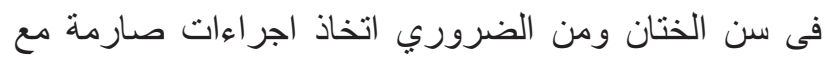
الأطباء و الممرضات الذين يقو مون بتلك العمليات.

كما ينبغي على نقابة الأطباء أن تتخذ تدابيراً عقابية ضد الأطباء الذين يمارسون تلك العادة بسحب تراخيص عملهم. وأن تسلط وسائل الاعلام الضوء على الحالات التي يتم إدانة الأطباء فيها،

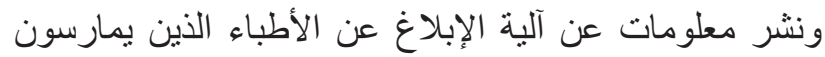
عمليات ختان الإناث تحت مسميات مختلفة.

\section{توصية ه: خفض الطلب علي ختان الاناث} تشير نتائج هذه الدراسة إلى أهمية مقاومة الخطاب الثنائع و المضلل الذي يصوَّر ممارسة ختان الإناث على أنها عملية

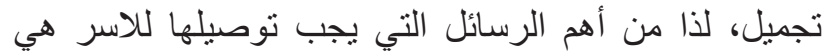

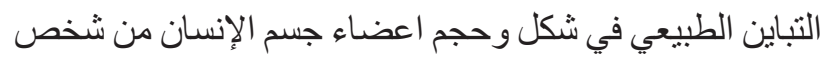
لاخر وتقديم معلومات حول وظائف الأعضاء التناسلية للذكور

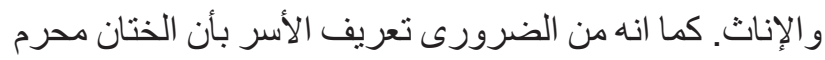

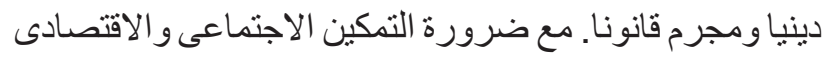

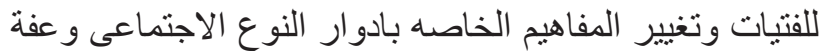

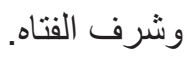

\section{توصية 7 : إجراء المزيد من البحوث حول}

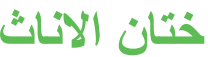

ان القضاء على ظاهرة تطبيب ختان الاناث يتطلب مزيدًا من

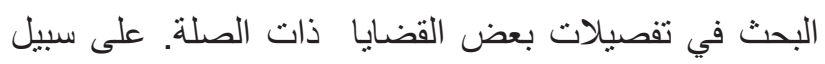

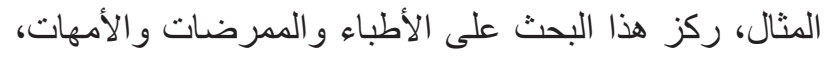
ولم يتضمن أسر مقدمي الرعاية الصحية والألي الذي يعد أمراً

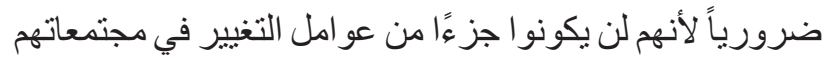

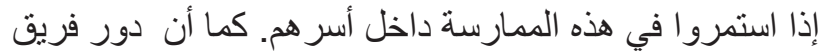

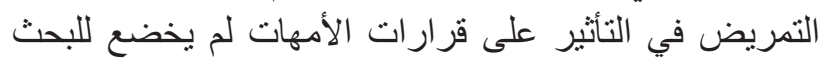

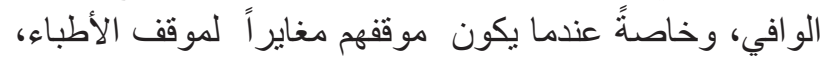

بناتهن تحت مسمى عملية تجميل ويرجع جزء كبير من هذا

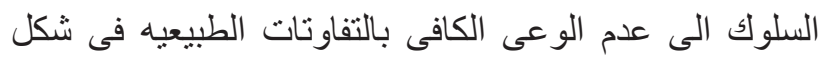

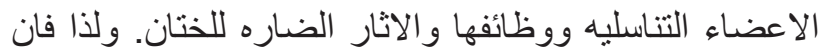

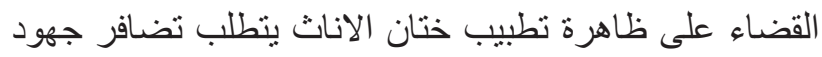
العديد من الجهات من اجل التصدى للاطباء الذين يقومون

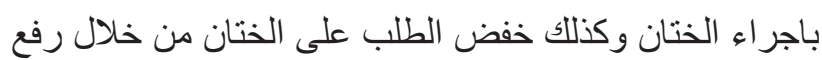
وعى الاسر بمضاره طويلة وقصيرة المدى.

توصية ا : ثطوير المناهج في كليات الطب و التمريض

بدأت أول خطوة في الاتجاه الصحيح مع تأييد نقابة الأطباء

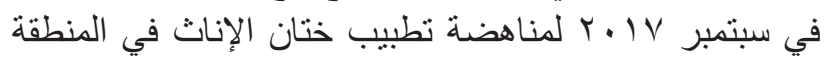

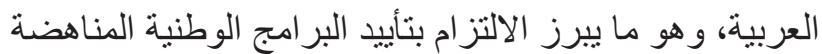

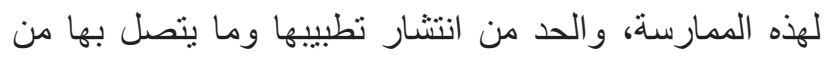

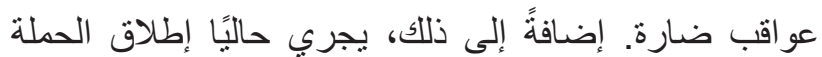

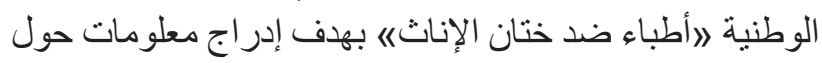

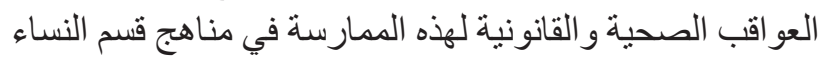
و التوليد بكليات الطب ب Y Y جامعة حكومية وخاصة.

ومن الضروري فى هذا الثأن أن تنتاول المناهج ختان الإناث

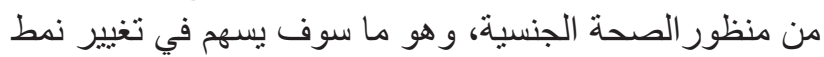

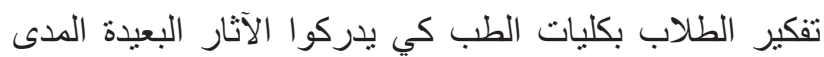

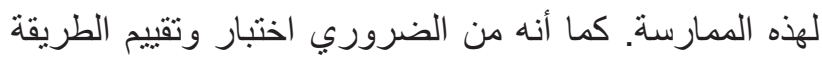

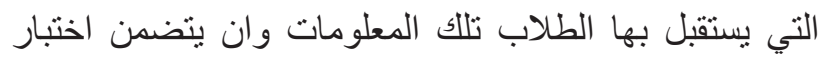

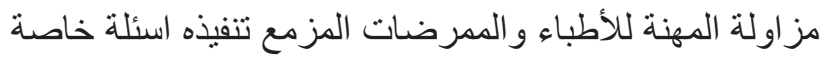

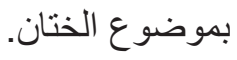

\section{ثوصية ب : ثعزيز مهار ات المشورة والإرشاد

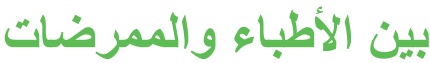

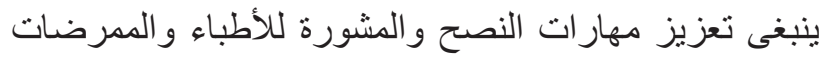

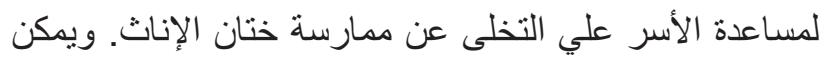

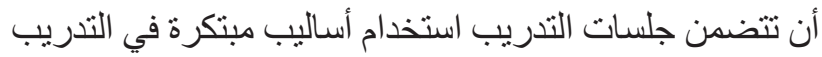

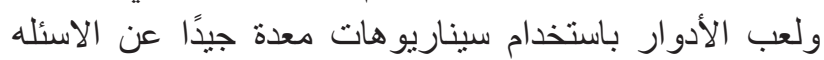
و الاستشار ات المختلفه التى تطرحها الامهات، وكيفية التعامل

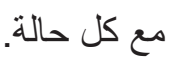

\section{تو صية با : ثلدريب جميع أعضاء الفريق الصحي

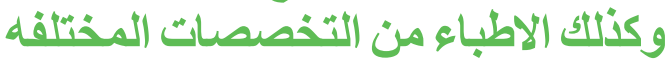

يجب ان يشمل التدريب الممارسين العموميين و اخصائى النساء

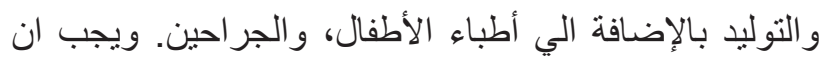


Hassanin IMA, Saleh R, Bedaiwy AA, Peterson RS, Bedaiwy MA. 2008. Prevalence of female genital cutting in Upper Egypt: 6 years after enforcement of prohibition law. Reproductive Biomedicine Online, 16:27-31.

Modrek S and Liu J X. 2013. Exploration of pathways related to the decline in female circumcision in Egypt. BMC Public Health, 13(1), 921.

Modrek S and Sieverding M. 2016. Mother, Daughter, Doctor: Medical professionals and mothers' decision-making about female genital mutilation/cutting in Egypt. Studies in Family Planning, 47(2), pp.111-202.

WHO (2010). Global Strategy to Stop HealthCare Providers from Performing Female Genital Mutilation. Geneva: World Health Organization

World Health Organization. (2008). Eliminatt ing female genital mutilation: an interagency statement - OHCHR, UNAIDS, UNDP, UNECA, UNESCO, UNFPA, UNHCR, UNICEF, UNIFEM, WHO. Geneva: World Health Organization. http://www.who.int/iris/handle/10665/43839

\section{شكر وتقدير}

يتقدم مجلس السكان الدولى بالثكر و التقدير لادارة التنميه

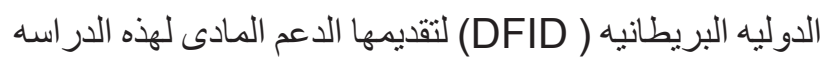
من خلال البرنامج البحثى للتخلى عن ظاهرة ختان الاناث.

والثكر موصول لاعضاء البرنامج القومى لـناهضة

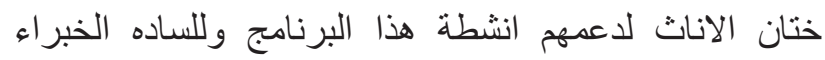
والمتخصصين الذين شاركوا فى اللجنه الاستشاريه الخاصنه بهذه الدر اسه و الذين اثرو ا الدر اسه بافكار هم ومقتر احاتهم.

كما يتقدم المجلس بالثكر للأستاذه الدكتوره اميمه الجبالى و الدكتوره ميريت عزيز لقيامهما باجر اء هذه الدر اسة. لئ.

واخيرا نتقدم بالثكر لفريق العمل بمجلس السكان الدولى الذين

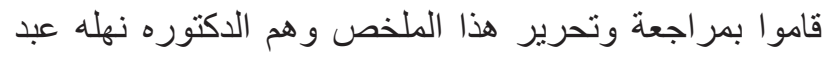

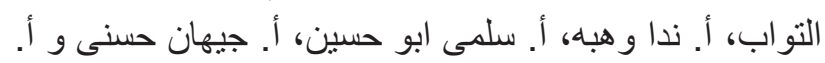
مونيكا ماهر.
و هو أمر مهم وينبغي تضمينه في دراسات إضافية للبحث في كيفية الاستفادة من دور أعضاء الفريق الطبي المختلفين. وأخيرا فانه بحكم ان هذه در اسه اعتمدت على المنهج الكيفى فان العان العينه

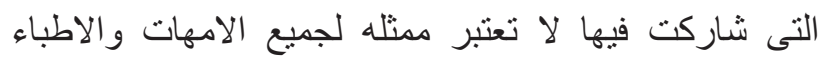
و الممرضات فى مصر لذا فمن الضروري فئات استخدام منهجية

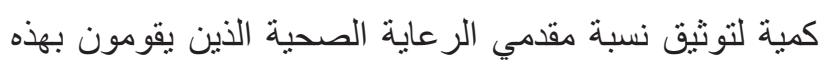
الممارسة أو الذين يعتقدون بأهميتها.

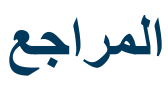

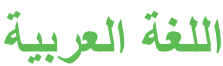

دعاء خليفة. يناير VI V. Y. الأول مرة فى مصرالحبس

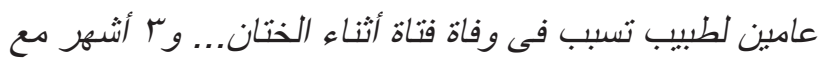
إيقاف التنفيذ للابه" ـ الأهرام

http://www.ahram.org.eg/NewsQ/356555.aspx

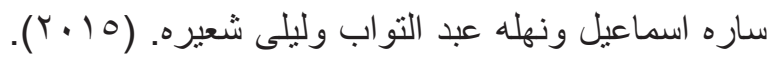

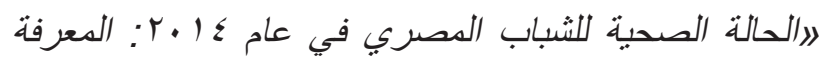

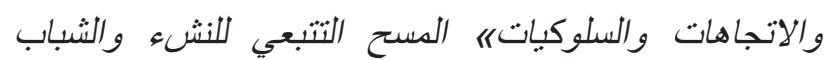

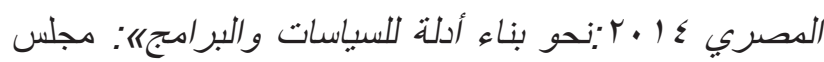

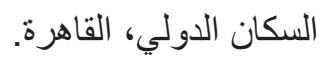

ساره غطاس ونهله عبد التواب وسلمى ابو حسين. (7 1 ؟).

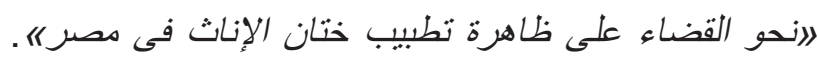
مجلس السكان الدولي، القاهرة.

http://www.popcouncil.org/uploads/ pdfs/2016RH_EndMedFGM-Egypt_ar.pdf

$$
\begin{aligned}
& \text { لؤي علي. ب يونيو 17 أب. رادار الإفتاء: ختان الإناث } \\
& \text { مخالف للشريعة و القانونه ـ اليوم السابع }
\end{aligned}
$$

https://goo.gl/TJVK2b

$$
\begin{aligned}
& \text { وزارة الصحة والسكان (مصر)، و الزناتي ومشاركوه }
\end{aligned}
$$

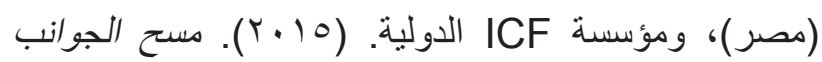

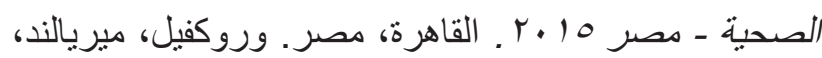

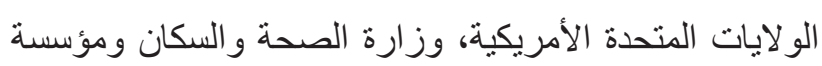

$$
\begin{aligned}
& \text { ICF } \\
& \text { اللغة الانبليزية }
\end{aligned}
$$

Barsoum G, Rifaat N, El-Gibaly O, Elwan N, Forcier N. 2009. Toward FGM-Free Villages in Egypt: A Mid-Term Evaluation and Documentation of the FGM-Free Village Project. Cairo: Population Council. 


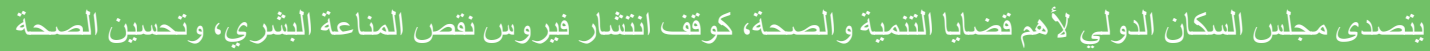

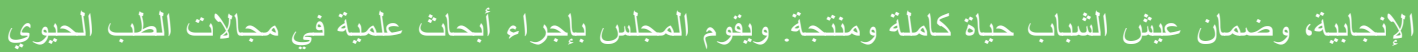

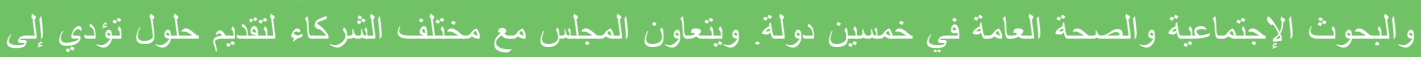

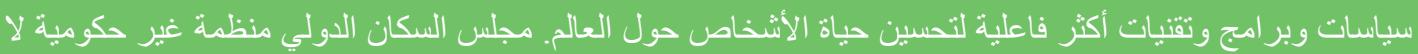

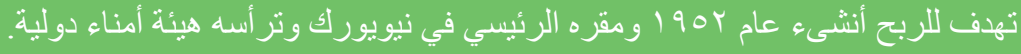

Population Council One Dag Hammarskjold Plaza New York, NY 10017

$$
\begin{aligned}
& \text { مجلس السكان الدولي _ مصر }
\end{aligned}
$$

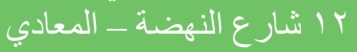

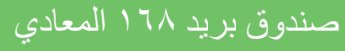

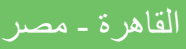

$$
\begin{aligned}
& \text { I IVYA }
\end{aligned}
$$

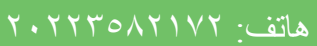

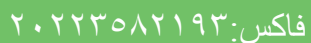

الموقع الاكتروني: WWw.popcouncil.org

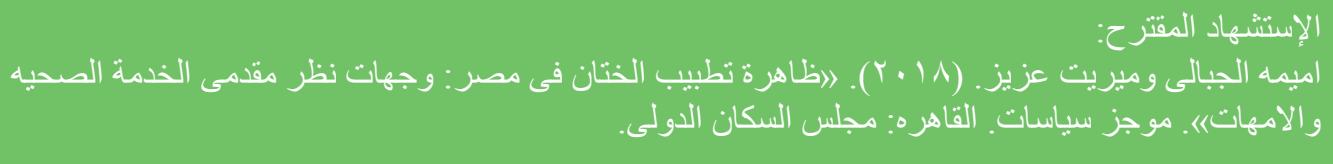

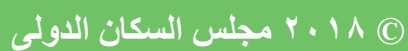

